\title{
Assessment of the suitability of gravel wash mud as raw material for the synthesis of an alkali-activated binder
}

\author{
Vishojit Bahadur Thapa, Danièle Waldmann, Jean-Frank Wagner, André Lecomte
}

1 Vishojit Bahadur Thapa, Laboratory of Solid Structures, University of Luxembourg.

2 Danièle Waldmann, Laboratory of Solid Structures, University of Luxembourg, Tel.: +35246 66445279 ,

3 E-mail: daniele.waldmann@uni.lu.

4 Jean-Frank Wagner, Department of Geology, University of Trier.

5 André Lecomte, Institut Jean Lamour, University of Lorraine, Nancy, France.

6 Abstract - Gravel wash mud (GWM), a waste product from gravel mining was dried and processed into

7 a fine powder to be activated by different concentrations of sodium hydroxide $(\mathrm{NaOH})$ solutions for the

8 synthesis of an alkali-activated binder. The GWM powders were thermally treated at five different

9 calcination temperatures $550,650,750,850$ and $950^{\circ} \mathrm{C}$. The characterisation of the raw material 10 comprises the particle size distribution (PSD) by laser granulometry, the chemical and mineralogical 11 composition by X-ray fluorescence and X-ray diffraction analysis respectively, and simultaneous thermal 12 analysis. The performance of the alkali-activated binders were examined using compression strength tests 13 and the microstructure was observed using scanning electron microscopy (SEM). The GWM was 14 classified as an aluminosilicate raw material with kaolinite and illite as main clay minerals. Furthermore, 15 a mean particle size around $6.50 \mu \mathrm{m}$ was determined for the uncalcined and calcined GWM powders. The 16 SEM images of the developed binders showed the formation of a compact microstructure, however, 17 relatively low strengths were achieved. This preliminary study highlights an example of an 18 aluminosilicate prime material, which shows very promising chemical and mineralogical characteristics, 19 but its suitability for alkaline activation without further additives was not confirmed as far as performance20 based criteria are considered.

21 Keywords - Gravel wash mud, thermally activated clays, alkali-activated binder, illite, kaolinite 


\section{INTRODUCTION}

23 Today's trend of revalorising waste products or industrial by-products to reduce the use of Ordinary

24 Portland Cement (OPC) in building or road constructions has become an ambitious goal and a key

25 objective of current political strategies, industries and research institutions (Friedlingstein et al., 2014;

26 Garcia-Gusano et al., 2015; Liu et al., 2015). Concrete, mainly based on OPC, is stated as the second

27 most used material in the world after water and its production generates up to $5 \%$ of the overall annual

$28 \mathrm{CO}_{2}$ emissions worldwide. One of the main factors responsible for the unfavourable ecological

29 performance of OPC is the high $\mathrm{CO}_{2}$ emissions linked to the cement production processes like clinker

30 burning including the chemical conversion of limestone $\left(\mathrm{CaCO}_{3}\right)$ into lime $(\mathrm{CaO})$ and the emissions

31 related to the fossil fuel combustion during cement production (Salas et al., 2016). Nevertheless, the

32 current demand for cementitious binder is reaching record values each year and this trend is likely to

33 increase. However, the incentive of developing sustainable and robust building concepts using alternative

34 construction materials has become increasingly relevant. Therefore, there is a growing challenge in the

35 research communities to develop new, durable and environmental friendly binders as an alternative to

36 OPC binders (Shi et al., 2011).

37 The concepts of alkali-activated binders or geopolymer cements are intensively investigated and

38 discussed as a very promising alternative to OPC. However, even if the concepts of alkali-activated

39 materials and the geopolymer technology are researched since last mid-century, there are discrepancies

40 and no overall accepted consensus considering the terminology of these materials. Fig. 1 shows a short

41 illustration of the general differences between alkali-activated binders and geopolymers in terms of

42 characteristics of the raw materials, activating solutions and reaction mechanisms. 


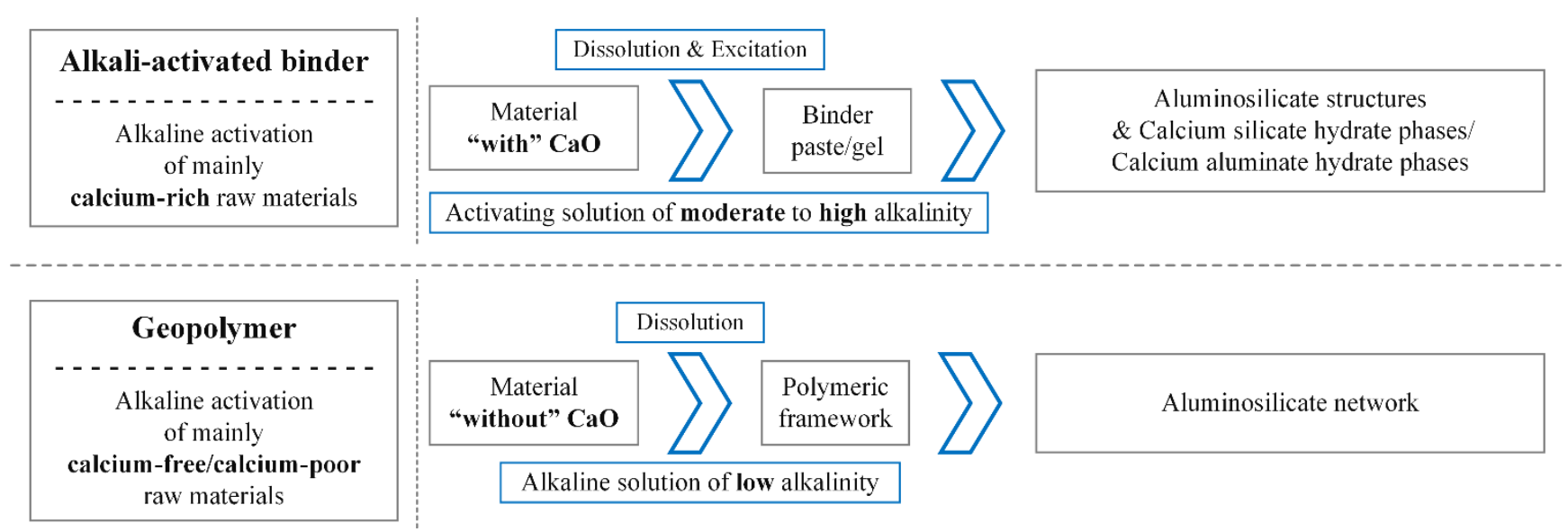

Fig. 1: Overview of the general reaction mechanisms of alkali-activated binder and geopolymer Glukhovsky (1959) was the pioneer in this field of research as he extensively studied the presence of analcime phases, which are classified as zeolites, in the cements of ancient constructions and later developed binders made from aluminosilicates in reaction with alkaline industrial wastes, which he named "soil silicate concrete" and "soil cements". The early investigations on alkali-activated binders mainly focused on the activation of blast furnace slag, a by-product of the metallurgical industry. After, the next wave of interest raised after the results of Davidovits $(1979,1994)$, who developed and patented a novel binder (Davidovits and Sawyer, 1985; Heitsmann et al., 1987) which he named "geopolymer cement". The first geopolymer binder was a slag-based geopolymer cement, which consisted of metakaolin, blast furnace slag and alkali silicate. The main driver for the development of this technology is the lower environmental impact compared to OPC technology. Several authors have evaluated the $\mathrm{CO}_{2}$ emissions related to the production of these binders and have stated significant reductions of up to $80 \%$ lower $\mathrm{CO}_{2}$ emissions compared to cement production (Davidovits et al., 1990; Provis and Van Deventer, 2009). Further benefits over conventional concrete is the rapid strength gain while reaching the maximal strength at early hours and the development of a durable and compact microstructure (Davidovits, 1994). Moreover, higher thermal resistance, higher resistance to chemical attack, low permeability and better passivation of the steel reinforcement have been identified (Pacheco-Torgal et al., 2012; Aguirre-Guerrero et al., 2017). Finally, the production of alkali-activated binders or geopolymer cements provides a sustainable and viable alternative use for "waste" materials, which have to be very uneconomically disposed in landfills. 
64 Subsequent studies have been carried out based on these original material concepts and various authors

65 have contributed by their research to the understanding of the chemical mechanism and the development 66 of alkaline binders (Glukhovsky, 1980; Shi et al., 1991; Roy et al., 1992; Wang et al., 1994; Wang and

67 Scrivener, 1995; Wang et al., 1995; Phair and Van Deventer, 2001; Escalante-Garcia et al., 2003;

68 Yunsheng et al., 2010; Le Saoût et al., 2011, Provis, 2014, 2017; Provis et al., 2015; Myers et al., 2017;

69 Wianglor et al., 2017).

70 However, the application of these binders in construction elements has already become challenging as the 71 price of these commercially available raw materials has risen over the last decades due to the high demand and the limited raw material availability, which is highly dependent on the primary industrial processes. Therefore, there is a trend to investigate on alternative prime materials to be revalorised for development of alkali-activated binders.

Sun et al. (2013) investigated on the synthesis of geopolymers out of waste ceramics, which were activated by alkali hydroxides and/or sodium/potassium silicate solutions. The maximum compressive strength for the synthesized geopolymer pastes measured after 28 days was $71.1 \mathrm{MPa}$ and favourable thermodynamically stable properties in terms of compressive strength evolution after thermal exposures were observed. Pacheco-Torgal et al. (2007) investigated on an alternative to OPC using tungsten mine waste mud as prime material. The mineralogical analysis indicated the presence of muscovite and quartz minerals. After activation with a mix of sodium hydroxide and sodium silicate, different fine aggregates were added and the new binders showed very high strength at early ages. The compressive strengths for the different mixtures measured after 28 days ranged from about 60 to $75 \mathrm{MPa}$. Poowancum et al. (2015) developed a geopolymer binder using water-treatment-sludge and rice husk ash as raw material. The alkaline activator used was a mixture of sodium hydroxide and sodium silicate and the resulting maximal strengths were around $16 \mathrm{MPa}$ for a rice husk content of 30\%. Chen et al. (2009) studied the practicability of calcined sludge from a drainage basin of a water reservoir as a precursor for alkaline activation into an inorganic polymer. The raw material consisted of a sludge containing fractions of silts and smectite clays with high content of aluminosilicates (around 85\%) and some impurities. The maximum compressive 
90 strength measured after 28 days was $56.2 \mathrm{MPa}$ using the raw material calcined at $850^{\circ} \mathrm{C}$.

91 Ferone et al. (2013) examined the potential of two clay sediments from different reservoirs, Occhito 92 and Sabetta, as raw material for the production of geopolymer binder. These sediments were subjected to 93 different calcination treatments and the binder was synthesized by mixing the calcined aluminosilicates 94 with $5 \mathrm{M} \mathrm{NaOH}$ solutions. After undergoing different curing conditions, the mechanical performance of 95 the samples was examined. In general, a rapid strength development was observed and the maximal 96 achieved compressive strength was around $10 \mathrm{MPa}$ for the samples made of Sabetta sediments. Finally, 97 the authors stated that the calcination temperature applied to the sediments plays a major role in the 98 effectiveness of the geopolymerisation.

99 Molino et al. (2014) performed a similar series of experiments on calcined sediments from Occhito 100 reservoir to synthesise binders using various concentrations of three different alkaline solutions, namely 101 sodium hydroxide solution, sodium aluminate solution and potassium aluminate solution. The authors recommended for impure precursors with low content of alumina to use alumina-containing activating 103 solutions as the samples activated with the sodium aluminate solution showed the best mechanical 104 performance and achieved compression strengths up to $7 \mathrm{MPa}$.

105 Recently, Messina et al. (2017) conducted investigations on the production of precast building elements 106 by the synthesis of geopolymer binders based on water potabilization sludge and clayey sediments, both 107 considered as waste products from reservoir management. After calcination, different proportions of the 108 raw materials were activated using a mixture of sodium silicate solution and a $14 \mathrm{M}$ sodium hydroxide 109 solution. The highest mechanical performance of the binders is stated around $23 \mathrm{MPa}$ in compression 110 strength and around $2 \mathrm{MPa}$ in tensile splitting strength.

111 In general, further research on potential alternative raw materials could approve their adequacy for OPC 112 replacement as a high compressive strength and low cost alkali-activated binder (Balek and Murat, 1996; 113 Buchwald et al., 2009a, 2009b; Yunsheng et al., 2010; Bignozzi et al., 2013; Gartner and Hirao, 2015).

114 In this work, the suitability of a waste material, gravel wash mud (GWM), as raw material for the 115 development of novel binders is examined by conducting different material characterisation techniques 
116 and experimental tests. The main focus relies on finding the best parameters for the calcination of the

117 GWM powders. An optimal calcination time and temperature range will be suggested after exposure to 118 selected high temperatures ranging from $550^{\circ} \mathrm{C}$ to $950^{\circ} \mathrm{C}$. The raw materials were characterised by

119 simultaneous thermal analysis (thermogravimetric analysis and differential scanning calorimetry, TG120 DSC), XRF and XRD. An optimal alkali-activated binder is selected based on mechanical testing and the 121 evaluations based on SEM images. The findings of this study will enrich the investigations on alkali122 activation of alternative raw materials to revalorise waste products economically and environmentally.

\section{EXPERIMENTAL PROCEDURE}

\section{$124 \quad 2.1 \quad$ Materials}

125 The prime material for this study, gravel wash mud (GWM), originates from Folschette (Rambrouch, 126 Luxembourg) and consists of wet deposits, which occur during gravel extraction, more precisely during 127 the washing of sand and gravel aggregates. The reddish brown mud is quite homogeneous and has a very 128 plastic consistency. The raw material was extracted from a storage basin and provided by Carrières Feidt 129 S.A., the operating company of the quarry. The geological analysis of the extraction site reveals that the 130 rock strata mainly consists of red sandstone (ger. Buntsandstein) in form of conglomeratic deposits of 131 sand and silt layers (Wagner, 1989; Lucius, 1948, 1950).

132 The GWM was dried at $105^{\circ} \mathrm{C}$ in a laboratory oven until reaching a constancy of mass $( \pm 2$ days) and 133 the dried prime material was ground into a fine powder. In the following process, the powder was calcined 134 for $1 \mathrm{~h}$ at different temperatures $550^{\circ} \mathrm{C}, 650^{\circ} \mathrm{C}, 750^{\circ} \mathrm{C}, 850^{\circ} \mathrm{C}$ and $950^{\circ} \mathrm{C}$ (heating rate of about $5^{\circ} \mathrm{C} / \mathrm{min}$ ) 135 in a laboratory chamber furnace with radiation heating (Nabertherm, Model N41/H).

136 The sand aggregates used were CEN-standard sands according to EN 196-1. The standard sand has a 137 characteristic grain size distribution with particle sizes ranging between $80 \mu \mathrm{m}$ and $2 \mathrm{~mm}$.

138 The hydroxide $(\mathrm{NaOH})$ solutions were prepared by dissolving commercially available $\mathrm{NaOH}$ pellets 139 ( $\geq 99 \%$ purity) in different portions of distilled water to obtain $\mathrm{NaOH}$ solutions of different molar 140 concentrations $(8 \mathrm{M}, 10 \mathrm{M}$ and $14 \mathrm{M})$. As the dissolution process of $\mathrm{NaOH}$ is an exothermic reaction, the 141 solutions were let to cool down in sealed bottles to avoid evaporation and the capture of carbon dioxide 
$142\left(\mathrm{CO}_{2}\right)$ from air to form sodium carbonate. The bottles were stored for $24 \mathrm{~h}$ at room temperature before 143 usage.

1442.2 Synthesis of the alkali-activated binder and mixing proportions

145 Two large series of alkali-activated binders were prepared (Fig. 2). The first series consists of binders,

146 which were prepared by mixing different calcined GWM powders with three concentrations of $\mathrm{NaOH}$ 147 solutions, $8 \mathrm{M}, 10 \mathrm{M}$ and $14 \mathrm{M}$. The second series of mixtures comprises the same mixing materials with 148 further addition of standard CEN sand at mass proportions of 3:1 to the calcined GWM powders. The 149 incorporation of aggregates allows to analyse the coverage of the grains by the binder and to verify the 150 formation of a more compact microstructure with higher mechanical performance. The liquid/solid (L/S) 151 ratio represents the relation between the contents by mass of the alkaline solution and the solid 152 constituents (GWM powders and sand). This ratio was kept constant for both series of mixtures at 0.7 , 153 respectively 0.8 (except 0.9 for $14 \mathrm{M}$ with addition of sand). Finally, nine specimens from each mixture 154 were prepared to have specimens for different curing times, 14 days, 28 days and 56 days ( 3 specimens 155 for each curing time). In total, 270 specimens were prepared using the compositions and mixing 156 proportions as listed in Table 1.

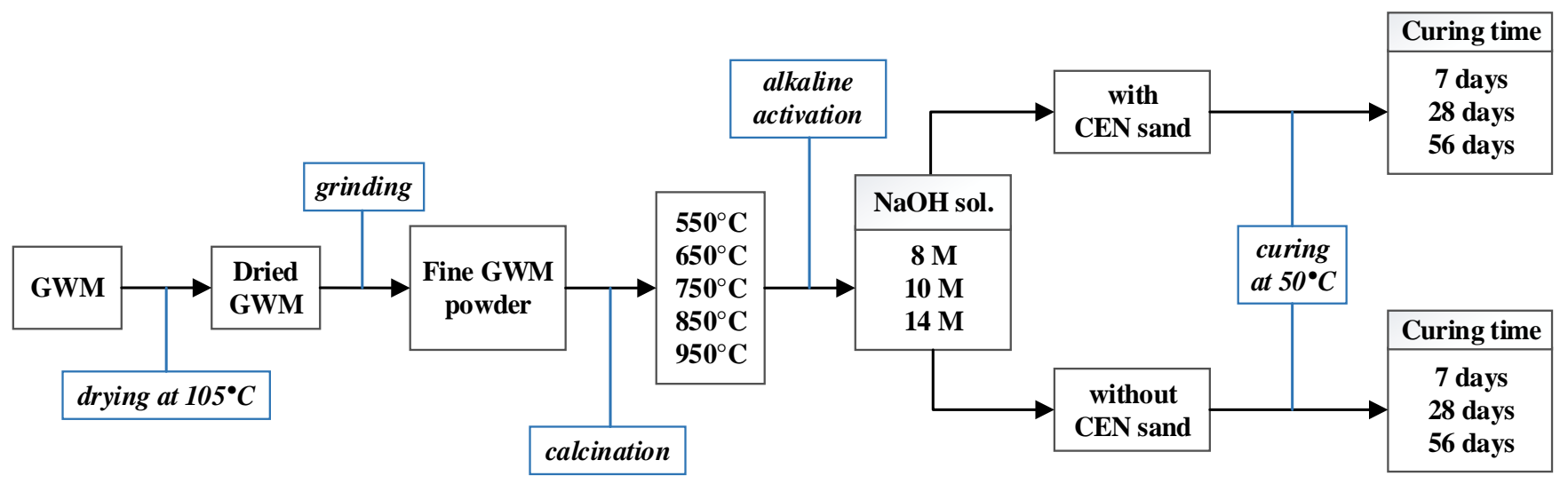

Fig. 2: Overview of the mixture composition of the alkali-activated binders 


\begin{tabular}{|c|c|c|c|c|c|c|c|c|c|}
\hline Sample ID & $\mathrm{CT}^{1}$ & $\mathbf{M}^{2}$ & $\mathrm{~L} / \mathrm{S}$ ratio $^{3}$ & $S: G^{4}$ & Sample ID & $\mathrm{CT}$ & M & L/S ratio & S:G \\
\hline G_550_8 & \multirow{3}{*}{$550^{\circ} \mathrm{C}$} & $8 \mathrm{M}$ & \multirow{15}{*}{0.7} & \multirow{15}{*}{ - } & GS_550_8 & \multirow{3}{*}{$550^{\circ} \mathrm{C}$} & $8 \mathrm{M}$ & 0.8 & \multirow{15}{*}{$3: 1$} \\
\hline G_550_10 & & $10 \mathrm{M}$ & & & GS_550_10 & & $10 \mathrm{M}$ & 0.8 & \\
\hline G_550_14 & & $14 \mathrm{M}$ & & & GS_550_14 & & $14 \mathrm{M}$ & 0.9 & \\
\hline G_650_8 & \multirow{3}{*}{$650^{\circ} \mathrm{C}$} & $8 \mathrm{M}$ & & & GS_650_8 & \multirow{3}{*}{$650^{\circ} \mathrm{C}$} & $8 \mathrm{M}$ & 0.8 & \\
\hline G_650_10 & & $10 \mathrm{M}$ & & & GS_650_10 & & $10 \mathrm{M}$ & 0.8 & \\
\hline G_650_14 & & $14 \mathrm{M}$ & & & GS_650_14 & & $14 \mathrm{M}$ & 0.9 & \\
\hline G_750_8 & \multirow{3}{*}{$750^{\circ} \mathrm{C}$} & $8 \mathrm{M}$ & & & GS_750_8 & \multirow{3}{*}{$750^{\circ} \mathrm{C}$} & $8 \mathrm{M}$ & 0.8 & \\
\hline G_750_10 & & $10 \mathrm{M}$ & & & GS_750_10 & & $10 \mathrm{M}$ & 0.8 & \\
\hline G_750_14 & & $14 \mathrm{M}$ & & & GS_750_14 & & $14 \mathrm{M}$ & 0.9 & \\
\hline G_850_8 & \multirow{3}{*}{$850^{\circ} \mathrm{C}$} & $8 \mathrm{M}$ & & & GS_850_8 & \multirow{3}{*}{$850^{\circ} \mathrm{C}$} & $8 \mathrm{M}$ & 0.8 & \\
\hline G_850_10 & & $10 \mathrm{M}$ & & & GS_850_10 & & $10 \mathrm{M}$ & 0.8 & \\
\hline G_850_14 & & $14 \mathrm{M}$ & & & GS_850_14 & & $14 \mathrm{M}$ & 0.9 & \\
\hline G_950_8 & \multirow{3}{*}{$950^{\circ} \mathrm{C}$} & $8 \mathrm{M}$ & & & GS_950_8 & \multirow{3}{*}{$950^{\circ} \mathrm{C}$} & $8 \mathrm{M}$ & 0.8 & \\
\hline G_950_10 & & $10 \mathrm{M}$ & & & GS_950_10 & & $10 \mathrm{M}$ & 0.8 & \\
\hline G_950_14 & & $14 \mathrm{M}$ & & & GS_950_14 & & $14 \mathrm{M}$ & 0.9 & \\
\hline \multirow{2}{*}{\multicolumn{5}{|c|}{$\begin{array}{l}{ }^{1} \mathrm{CT} \text { - Calcination temperature } \\
{ }^{2} \mathrm{M} \text { - Molarity of activating solution }\end{array}$}} & \multirow{2}{*}{\multicolumn{4}{|c|}{$\begin{array}{l}{ }^{3} \mathrm{~L} / \mathrm{S} \text { - Liquid to solid (mass) ratio } \\
{ }^{4} \mathrm{~S}: \mathrm{G}-\text { Sand to GWM (mass) ratio }\end{array}$}} & \\
\hline & & & & & & & & & \\
\hline \multicolumn{9}{|c|}{$\begin{array}{l}\text { Further information: } \\
\text { - Designation principle: } G(S) \text { CT_M with “G” for GWM \& "GS" for GWM with sand } \\
\text { - } 3 \text { specimens per curing time (14 days, } 28 \text { days and } 56 \text { days) were prepared for each mixture }\end{array}$} & \\
\hline
\end{tabular}

Table 1: Mixing proportions of all investigated alkali-activated binders

The mixtures without additional aggregates were prepared by adding the calcined GWM powder in a

mixing bowl and by mechanically mixing the powders at a speed of $125 \mathrm{rpm}$ for $90 \mathrm{~s}$ with gradual addition

of the alkaline solution. Subsequently, the mixture was mixed at a speed of $250 \mathrm{rpm}$ for $90 \mathrm{~s}$ until a good

164 processable compound has formed. The mixing procedure of the binders with additional aggregates

165 consists of primarily preparing the binder (GWM and alkaline solution; at $125 \mathrm{rpm}$ for 90s). Afterwards,

166 the CEN-standard sand was gradually added and mechanically intermixed at a mixing speed of $125 \mathrm{rpm}$

167 for $60 \mathrm{~s}$ and later at $250 \mathrm{rpm}$ for $90 \mathrm{~s}$ until stoppage.

168 The prepared binder compounds were poured in prismatic moulds $\left(40 \times 40 \times 160 \mathrm{~mm}^{3}\right)$ and vibrated for

1697 seconds. Then, the moulds were covered using plastic plates of $5 \mathrm{~mm}$ thickness and additionally

170 wrapped in cellophane foil to prevent desiccation of the samples and rapid loss of moisture. The mixtures

171 were let to cure inside the moulds in a ventilated oven at $50^{\circ} \mathrm{C}$. After demoulding, the specimens were

172 sealed in cellophane foil and stored at $50^{\circ} \mathrm{C}$ until 24 hours before the compression strength test. 
$174 \quad 3.1$ Physical and chemical characterization of the GWM powders

175 The PSD of the powders were evaluated by laser granulometry using a modular analysis system 176 (HELOS and RODOS from Sympatec GmbH). Laser granulometry follows the methods of laser 177 diffraction based on Fraunhofer diffraction physics (Cowley, 1995). This measurement unit is applicable 178 on all kind of dry powders. The particle size distribution of the GWM powders is shown in Fig. 3. The 179 particle size mainly comprises within a range of 1 to $35 \mu \mathrm{m}$ with a mean particle size (d50) around $1806.50 \mu \mathrm{m}$, whereas, comparatively mean particle size of cement powder ranges around 10-12 $\mu \mathrm{m}$. The PSD 181 analysis of the GWM powders calcined at different temperatures resulted in a similar grain size 182 distribution beside for the powders calcined at $850^{\circ} \mathrm{C}$ and $950^{\circ} \mathrm{C}$, where a slight shift of the curves to 183 coarser particle sizes was observed due to the clumping of the powders related to the effect of sintering 184 of fine clay particles (Aramide, 2015).

185 The specific surface area of the powder samples, determined following the BET method (Brunauer et 186 al., 1938), was at $14.5 \mathrm{~m}^{2} / \mathrm{g}$. Furthermore, the chemical composition of the GWM powder was determined using a wavelength dispersive X-ray fluorescence spectrometer (S4 Explorer from Bruker Corporation) 188 with a flexible integrated auto sampler. The samples were prepared by pelletisation of a mix of loose 189 GWM powder with wax in a ring using the pressed powder technique. The calcination parameters of the 190 GWM powders were verified by the study of mineralogical phase transition and thermal analysis. The 191 chemical composition of the GWM powder is listed in Table 2. The analysis of the chemical constitution 192 verifies that the raw material mainly consists of aluminosilicate particles with primary chemical elements 193 of $\mathrm{SiO}_{2}, \mathrm{Al}_{2} \mathrm{O}_{3}$ and $\mathrm{Fe}_{2} \mathrm{O}_{3}$. 


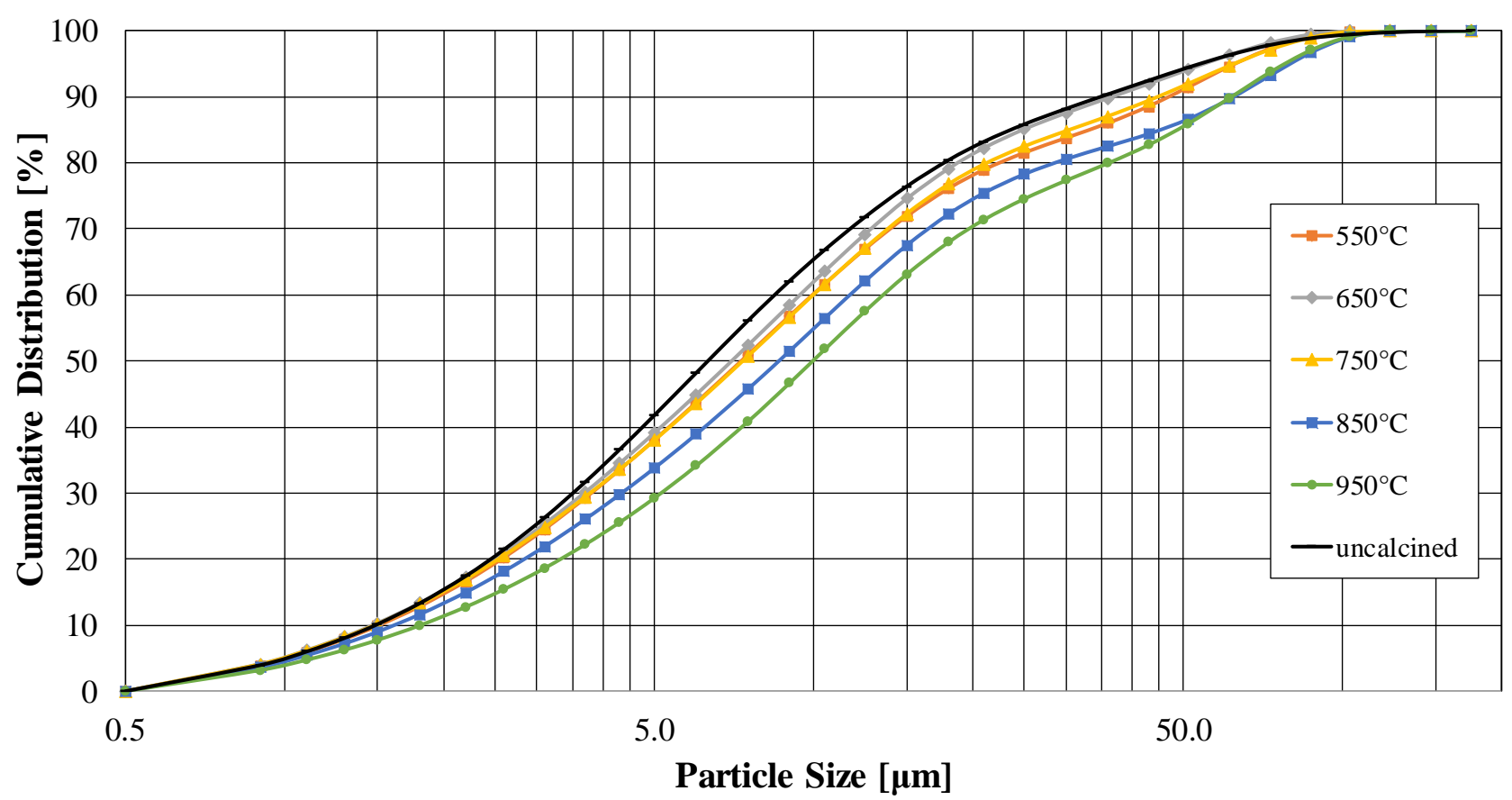

Fig. 3: Particle size distribution of the uncalcined and calcined GWM powders measured by laser granulometry

\begin{tabular}{cc}
\hline $\begin{array}{c}\text { Element } \\
{[-]}\end{array}$ & $\begin{array}{c}\text { Content } \\
{[\%]}\end{array}$ \\
\hline $\mathrm{SiO}_{2}$ & 64.95 \\
$\mathrm{Al}_{2} \mathbf{O}_{3}$ & 19.98 \\
$\mathrm{Fe}_{2} \mathbf{O}_{3}$ & 9.02 \\
$\mathbf{K}_{2} \mathbf{O}$ & 3.27 \\
$\mathbf{M g O}$ & 1.30 \\
$\mathbf{T i O}_{2}$ & 0.70 \\
$\mathbf{C a O}$ & 0.26 \\
\hline
\end{tabular}

Table 2: Chemical composition of the uncalcined GWM particles determined by XRF spectrometry

\subsection{Mineralogical composition and thermal analysis}

199 The GWM powders require thermal treatment at high temperatures (calcination) to increase the 200 reactivity of the aluminosilicate materials by dehydration, dehydroxylation and change of the phase 201 composition. This thermal decomposition provides a high-energy, distorted and amorphous raw material, which is favourable for the alkaline dissolution process.

203 The mineralogy of the uncalcined and the different calcined GWM powders were studied by XRD analysis. The X-ray diffractograms were collected with a D4 ENDEAVOR (Bruker Corporation) powder $\mathrm{X}$-ray diffractometer using $\mathrm{Cu} \mathrm{K} \alpha$ radiation at standard scanning parameters. A quantitative analysis was performed following the Rietveld refinement principles (TOPAS, Bruker Corporation) (Paul, 2005). A 
207 quantitative phase analysis was applied instead of a qualitative crystalline phase analysis to quantify the

208 formed amorphous phases due to different calcination temperatures.

209 Beside the analysis of the mineralogical compositions, this evaluation in combination with the

210 simultaneous thermal analysis (STA) enables to determine an optimum range for duration and

211 temperature level for the thermal treatment of the GWM powder. The sample preparation for XRD

212 analysis was the same as for the previously mentioned XRF analysis.

213 A quantitative XRD analysis has been carried out for the uncalcined and calcined GWM powders at 214 temperatures of $550^{\circ} \mathrm{C}, 650^{\circ} \mathrm{C}, 750^{\circ} \mathrm{C}, 850^{\circ} \mathrm{C}$ and $950^{\circ} \mathrm{C}$ for 1 hour. The calcination time was set to 1 hour

215 based on findings of preliminary tests and suggestions from previous research works (Sabir et al., 2001;

216 Diffo et al., 2015). Fig. 4 illustrates the reduction of crystalline aluminosilicate minerals with the

217 development of new mineral phases and the rise of amorphous phases regarding the calcination

218 temperatures. First of all, the mineralogy verifies that the aluminosilicate raw material consists of 219 kaolinite and illite as main clay mineral. The dominant phases in all samples are the quartz minerals, 220 followed by clay minerals, muscovite, hematite and the amorphous portions. In addition, from the 221 qualitative analysis of the GWM powder, the presence of low amounts of chlorite was detected, but could 222 not be considered in the quantitative analysis. Higher calcination temperatures lead to transformation of 223 the clay minerals into XRD amorphous phases. In fact, two stages of dehydroxylation can be observed. 224 First, kaolinite is entirely transformed to metakaolinite at temperatures around $600^{\circ} \mathrm{C}$, whereas illite 225 becomes amorphous at higher temperatures around $900^{\circ} \mathrm{C}$. Furthermore, the content of muscovite is 226 reduced leading to an increase in the content of $\mathrm{KAl}_{3} \mathrm{Si}_{3} \mathrm{O}_{11}$, which is a dehydroxilised, crystalline meta227 phase of muscovite. Independent on the calcination temperature, the hematite content remains almost 228 constant over all calcination temperatures.

229 The STA consists of a measurement concept that allows to perform thermogravimetric analysis (TGA) 230 and differential scanning calorimetry (DSC) simultaneously on a single measurement unit. The analysis 231 was carried out from room temperature until $1000^{\circ} \mathrm{C}$ at a heating rate of $10^{\circ} \mathrm{C} / \mathrm{min}$ in a controlled nitrogen 232 gas atmosphere. 
233 The results of the STA analysis (TG-DSC) are presented in Fig. 5. The TG curve shows two mass 234 reduction stages (Total: $-2.62 \%$ ) of the investigated sample before $900^{\circ} \mathrm{C}$. From about $30^{\circ} \mathrm{C}$ to $430^{\circ} \mathrm{C}$, a 235 first gradual mass loss $(-0.54 \%)$ is observed due to the evaporation of adhesion water of the 236 aluminosilicate minerals and the burnout of organic matters inside the samples. Furthermore, a greater 237 decrease in mass $(-2.09 \%)$ is observed due to the further dehydration of structural water and the 238 dehydroxylation of the crystalline aluminosilicate minerals from $500^{\circ} \mathrm{C}$ to $975^{\circ} \mathrm{C}$ until a constant mass 239 state is reached. The DSC curve confirms the process of dehydroxylation of the aluminosilicate matrix, 240 followed by phase transition of the quartz minerals as an endothermic peak is observed at around $575.8^{\circ} \mathrm{C}$ 241 (quartz inversion). Moreover, the crystallization of the oxides is marked by an exothermic peak at $980^{\circ} \mathrm{C}$. 242 The findings of both analysis, mineralogical and thermal, suggest thermal treatment of the GWM powder 243 within the range of $650^{\circ} \mathrm{C}-950^{\circ} \mathrm{C}$.

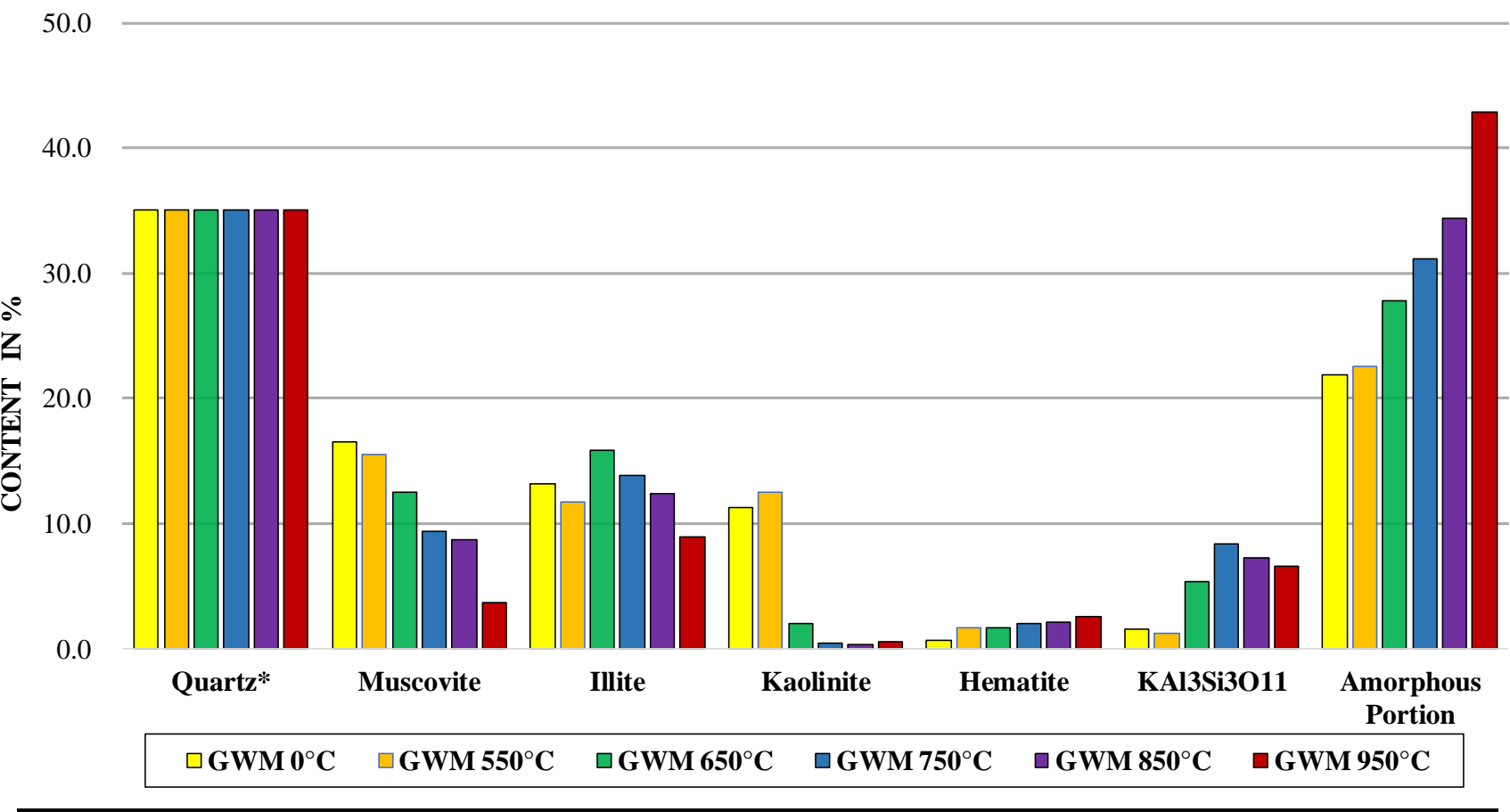

* Assumption: Quartz remains constant during the calcination at given temperatures. Quartz portion fixed at $35 \%$ to prevent errors from the normalization to $100 \%$ using the Rietveld analysis

Fig. 4: Results of quantitative X-ray diffraction analysis of the uncalcined and calcined GWM particles at various high temperatures 


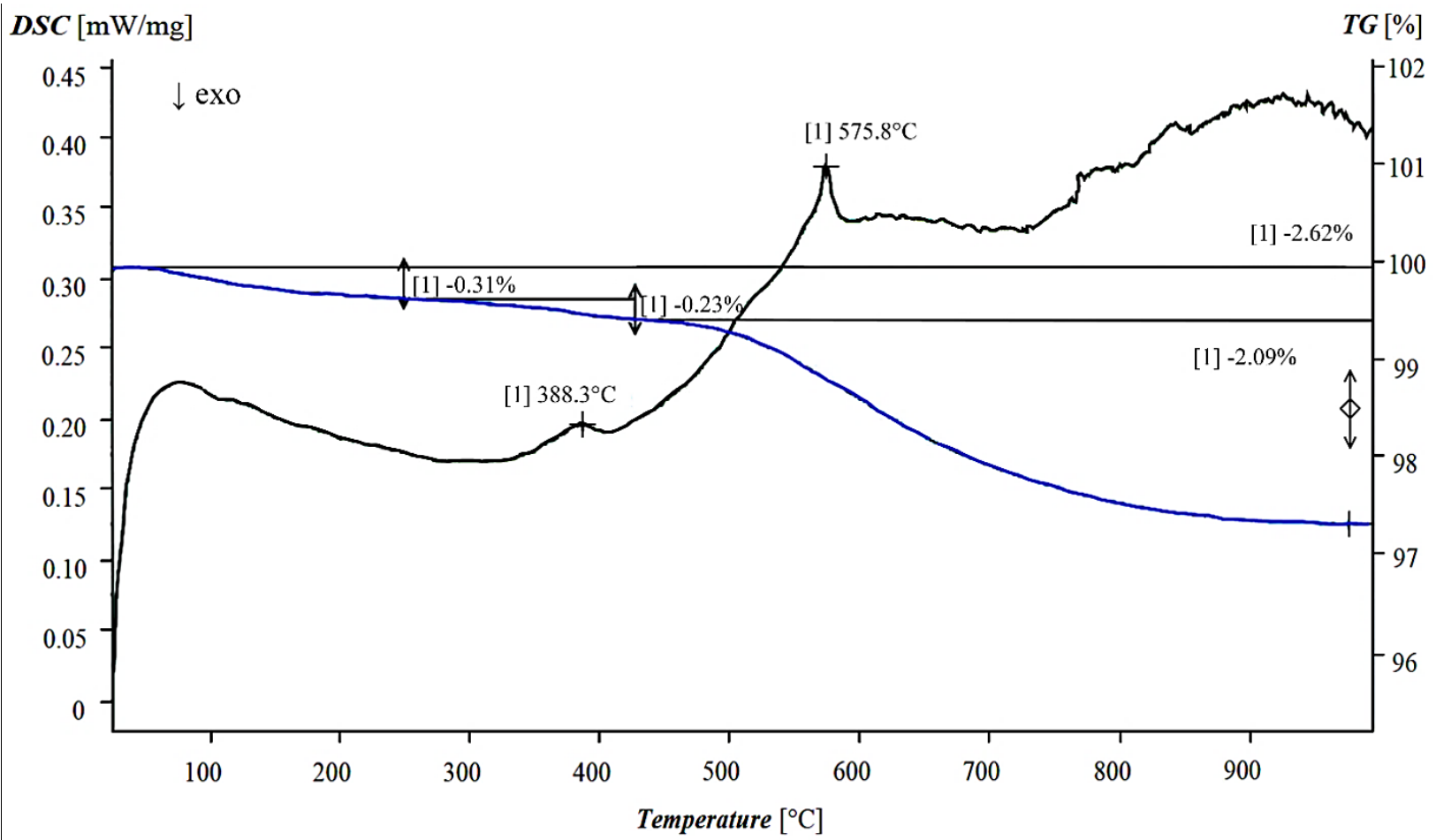

Fig. 5: Results of the STA analysis (TG-DSC) on the GWM powder

\section{$249 \quad 3.3 \quad$ Compressive strength}

250 The compressive strength was measured on three specimens of each mixture after 14 days, 28 days and

25156 days using a compression test plant (Toni Technik GmbH) with additional displacement transducers.

252 This measurement unit is optimised for compressive strength tests on prisms $\left(40 \times 40 \times 160 \mathrm{~mm}^{3}\right)$ according 253 to EN 196 standard. Unhardened specimens after 14 days, mainly specimens including GWM powder 254 calcined at $550^{\circ} \mathrm{C}$, were not compressed, as no sign of solidification was observable. Fig. 6 and Fig. 7 255 illustrates the strength development of the binders based on GWM powder calcined at different 256 temperatures without/with sand aggregates. The specimens made with GWM powder calcined at $550^{\circ} \mathrm{C}$ 257 showed very low compressive strengths and consequently low reactivity. It can be observed that for this 258 GWM powder a higher concentration of the $\mathrm{NaOH}$ solution dissolved higher portions of the unreactive 259 aluminosilicate particles and no dense structure could be built. This observation also verifies the 260 predictions from the mineralogical analysis discussed in section 3.2. In general, a higher thermal 261 treatment of the GWM powders resulted in a more reactive material, which, in combination with a higher 262 alkaline dissolution degree due to higher molarities of the alkaline solution, exhibited better compressive 
strengths. The highest compressive strength of $1.86 \mathrm{MPa}$ was achieved by specimens calcined at $950^{\circ} \mathrm{C}$

264 and activated using $14 \mathrm{M} \mathrm{NaOH}$ solution with sand aggregates. Finally, the results of the compression 265 strength test confirm the dependency of the performance of the GWM-based alkali-activated binder on 266 the calcination temperature of the aluminosilicate prime material, and respectively, its degree of 267 dissolubility in the alkaline medium.

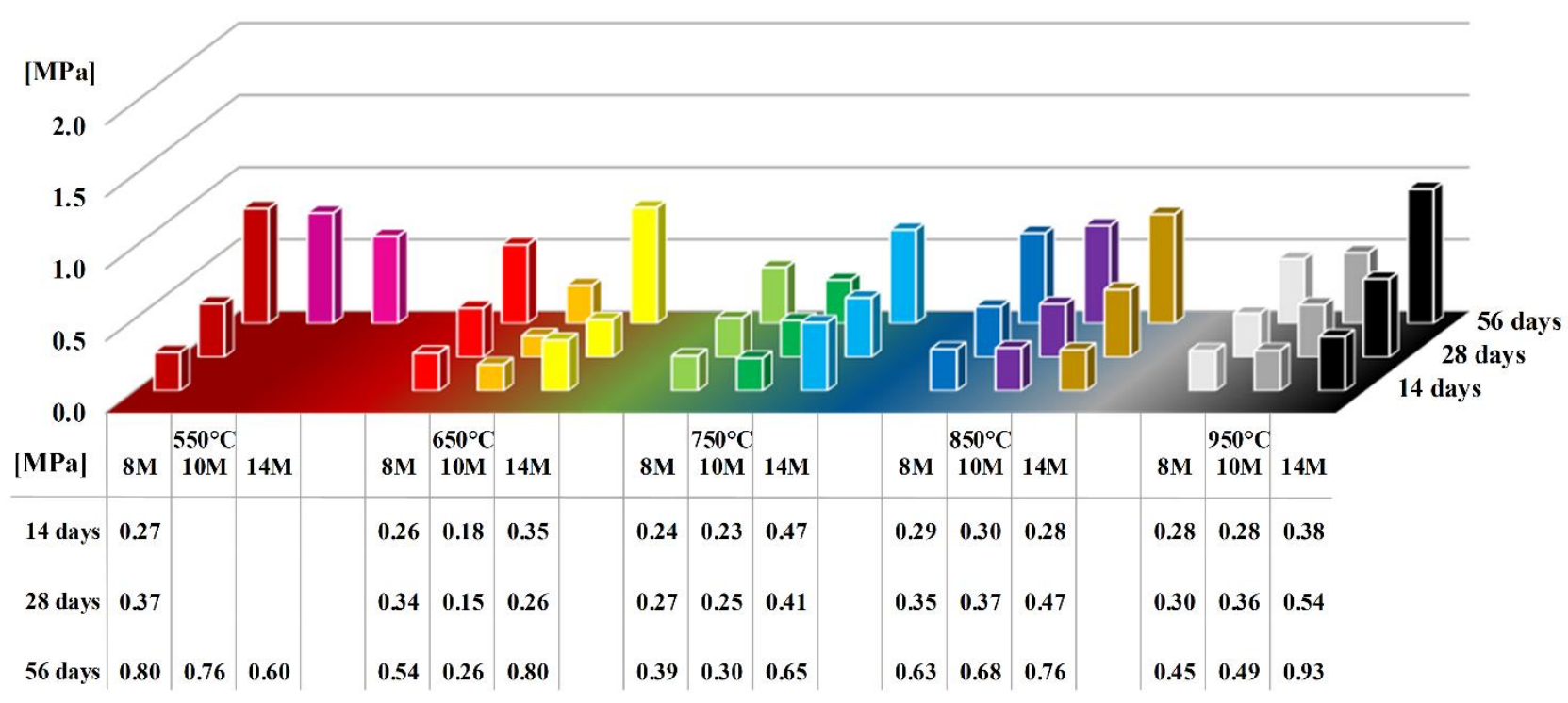

Fig. 6: Strength development of GWM-based binders without sand aggregates for varying calcination 270 temperatures, varying concentrations of $\mathrm{NaOH}$ solutions and concrete ages

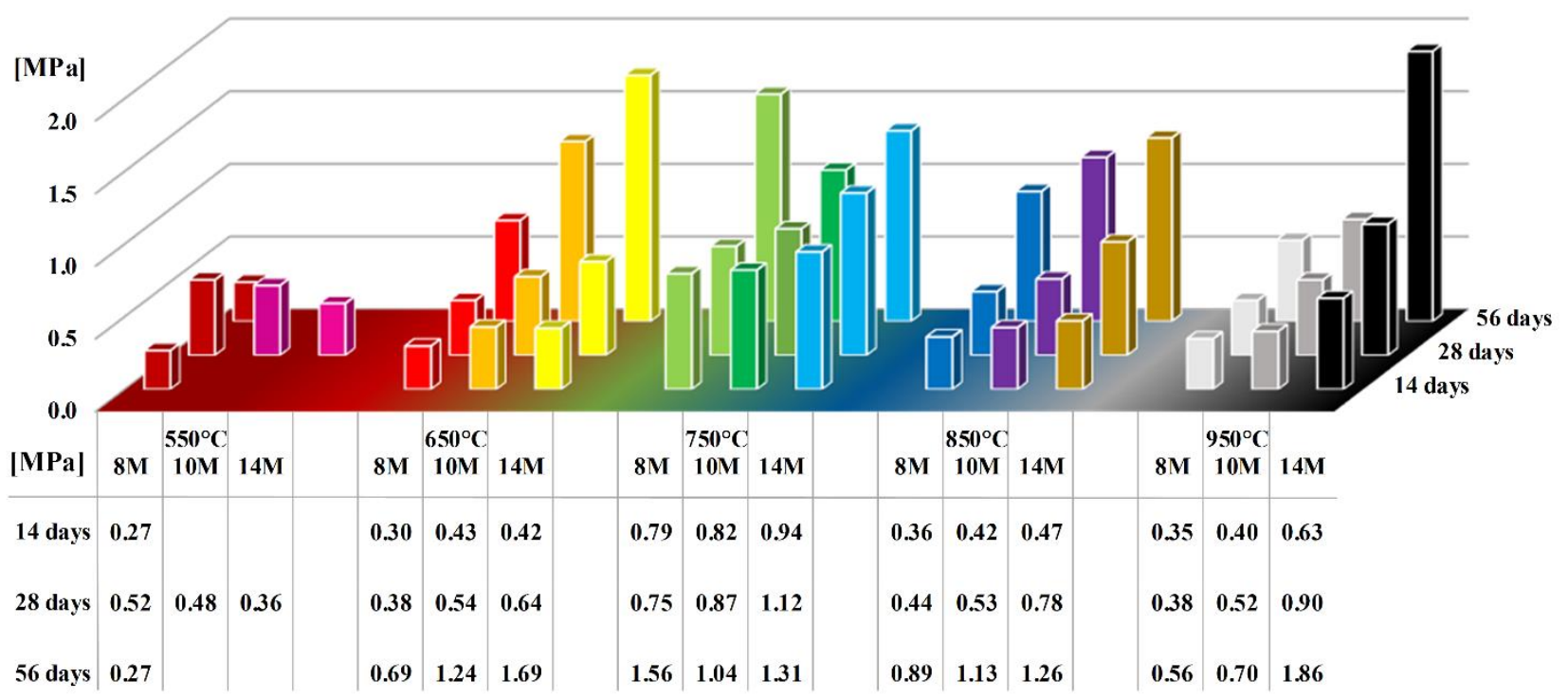

Fig. 7: Strength development of GWM-based binders with sand aggregates for varying calcination temperatures, varying concentrations of $\mathrm{NaOH}$ solutions and concrete ages 


\subsection{Analysis of the microstructure}

275 The microstructure of all binders was analysed by SEM using LEO 440 REM, which is a compact and 276 high performing SEM unit that enables high quality observations of structure surfaces down to $5 \mathrm{~nm}$ 277 realised by detection of secondary backscattered electrons from a high-energy beam of primary electrons 278 in a raster scan pattern.

279 The images of the microstructure of selected alkali-activated binders (Fig. 8) were obtained by 280 performing SEM on small fractions of the compressed specimens. Fig. 8.a-b show the microstructure of 281 the binders realised based on GWM powders calcined at $550^{\circ} \mathrm{C}$. The binder in Fig. 8.a shows a compact 282 composition, which envelops the quartz particle, whereas comparatively, the binder in Fig. 8.b shows a 283 more porous composition and the coverage of the quartz particle is loose and weak. As already supposed 284 in the mineralogical analysis (section 3.2) and supported by the compressive strength test (section 3.3), 285 these binders (using calcined $\mathrm{GWM}$ at $550^{\circ} \mathrm{C}$ ) possess highly disintegrated, low reactive aluminosilicate constituents formed by the dissolution in higher alkaline solutions, which lead to a weaker binder framework. In comparison with these binders (Fig. 8.c-f), binders realised on the basis of GWM powders with higher thermal treatment show larger flaky, plate-like meta-clay minerals and needle-like mineral 289 formations which provide larger reactive surfaces for the development of a compact microstructure.

290 Finally, Fig. 8.g-h presents the morphology of binders subjected to higher alkalinity and based on GWM powders calcined at higher temperatures. These microstructures present a well-formed morphology of the constituents resulting in a dense and compact matrix comprising flaky meta-clays, needle-like crystal 293 formations and amorphous material.

294 The GWM's fineness with its chemical and mineralogical composition provided an auspicious base to assess its suitability for the synthesis of an alkali-activated binder. Even though the developed microstructures showed a well-developed binder framework, the achieved compressive strengths were small. These results suggest that GWM without any further additives or processing is not recommended as a precursor for alkaline activation. This outcome can be explained by the low silica content in the binder compared to the alumina content, respectively, the lower portion of reactive clay minerals 
300 compared to the dominant quartz content from a mineralogical point of view. Thereby, the calcined 301 materials comprise lower contents of reactive meta-clays to take part in the reactions. In comparison, 302 hardened mixtures based on raw materials with higher contents of kaolinite can achieve compressive 303 strengths above 38.5 MPa (Kong et al., 2007) or 48.8 MPa (Tchakoute et al., 2015) depending on the 304 characteristics of the raw materials and the applied alkaline solution. 

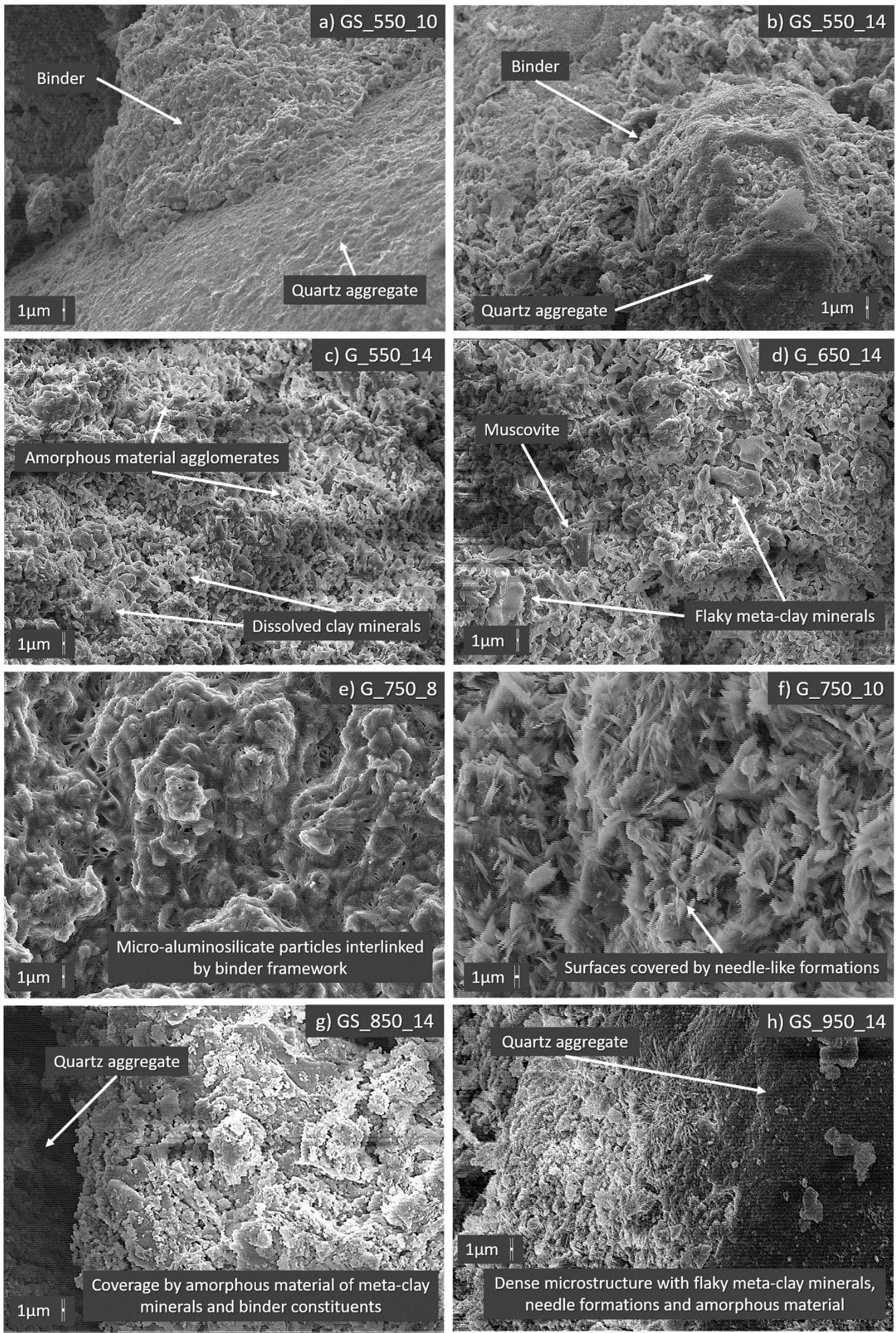

Fig. 8: Scanning electron micrographs of selected specimens showing the morphology of the constituents of the alkali-activated binders in the micron range (image scale of $1 \mu \mathrm{m}$; magnification up to

$3600 \mathrm{x})$ 


\section{Conclusion}

310 This study presents the results of investigations carried out on alkali-activated binder using calcined

311 GWM as prime material. The key findings from different material characterisation methods and 312 experimental tests on specimens are summarized below:

313 (1) The GWM powder consists of quartz with a moderate content of clay minerals (illite and

(4) The highest 56-day compressive strength of the binders was $1.86 \mathrm{MPa}$ and occurred for the mixture using GWM powder calcined at $950^{\circ} \mathrm{C}$ with a $14 \mathrm{M} \mathrm{NaOH}$ solution and mixed with sand aggregates.

(5) The microstructure presents a well-formed morphology of the constituents resulting in a dense and compact matrix comprising flaky meta-clays, needle-like mineral formations and amorphous material.

\section{3 binders.}


335 The authors gratefully acknowledge Carrières Feidt S.A. for the supply of the gavel wash mud (GWM), 336 Cimalux S.A. with its partner institution Wilhelm Dyckerhoff Institut (WDI) for their contributions in the material characterisation and Contern S.A. for the supply of required materials and tools.

Aguirre-Guerrero, A. M., Robayo-Salazar, R. A., \& de Gutiérrez, R. M. (2017). A novel geopolymer application: Coatings to protect reinforced concrete against corrosion. Applied Clay Science, 135, 437-446

Aramide, F. O., 2015. Effects of sintering temperature on the phase developments and mechanical properties ifon clay. Leonardo Journal of Sciences, 26, 67-82.

344 Balek, V., Murat, M., 1996. The emanation thermal analysis of kaolinite clay minerals. Thermochimica Acta, 282, 385-397.

Bignozzi, M. C., Manzi, S., Lancellotti, I., Kamseu, E., Barbieri, L., Leonelli, C., 2013. Mix-design and characterization of alkali activated materials based on metakaolin and ladle slag. Applied Clay Science, 73, 78-85.

Brunauer, S., Emmett, P. H., Teller, E., 1938. Adsorption of gases in multimolecular layers. Journal of the American chemical society, 60 (2), 309-319.

Buchwald, A., Hohmann, M., Posern, K., Brendler, E., 2009a. The suitability of thermally activated illite/smectite clay as raw material for geopolymer binders. Applied Clay Science, 46 (3), 300-304.

Buchwald, A., Vicent, M., Kriegel, R., Kaps, C., Monzó, M., Barba, A., 2009b. Geopolymeric binders with different fine fillers-phase transformations at high temperatures. Applied Clay Science, 46 (2), 190-195.

Chen, J. H., Huang, J. S., Chang, Y. W., 2009. A preliminary study of reservoir sludge as a raw material of inorganic polymers. Construction and Building Materials, 23 (10), 3264-3269.

Cowley, J. M., 1995. Diffraction physics. Elsevier. 
359 Davidovits, J., 1979. Synthesis of New High-Temperature Geo-Polymers for Reinforced 360 Plastics/Composites, SPE PACTFC 79, Society of Plastic Engineers, Brookfield Center, USA, pp. $361 \quad 151-154$

362 Davidovits, J., Comrie, D. C., Paterson, J. H., Ritcey, D. J., 1990. Geopolymeric concretes for 363 environmental protection. Concrete International, 12 (7), 30-40.

364 Davidovits, J., 1994. Properties of geopolymer cements. First international conference on alkaline 365 cements and concretes, Vol. 1, 131-149.

366 Davidovits, J., Sawyer, J. L., 1985. U.S. Patent No. 4,509,985, EP No.0153097.

367 Diffo, B. K., Elimbi, A., Cyr, M., Manga, J. D., Kouamo, H. T., 2015. Effect of the rate of calcination of 368 kaolin on the properties of metakaolin-based geopolymers. Journal of Asian Ceramic Societies, 3 (1), 130-138.

370 Escalante-García, J. I., Gorokhovsky, A. V., Mendoza, G., Fuentes, A. F., 2003. Effect of geothermal waste on strength and microstructure of alkali-activated slag cement mortars. Cement and concrete research, $33(10)$, 1567-1574.

Ferone, C., Colangelo, F., Cioffi, R., Montagnaro, F., Santoro, L., 2013. Use of reservoir clay sediments as raw materials for geopolymer binders. Advances in Applied Ceramics, 112 (4), 184-189.

375 Friedlingstein, P., Andrew, R. M., Rogelj, J., Peters, G. P., Canadell, J. G., Knutti, R., Luderer, G., Raupach, M. R., Schaeffer, M., van Vuuren, D. P., Le Quéré, C., 2014. Persistent growth of $\mathrm{CO}_{2}$ emissions and implications for reaching climate targets. Nature geoscience, 7 (10), 709-715.

García-Gusano, D., Cabal, H., Lechón, Y., 2015. Long-term behaviour of $\mathrm{CO}_{2}$ emissions from cement production in Spain: scenario analysis using an energy optimisation model. Journal of Cleaner $380 \quad$ Production, 99, 101-111.

381 Gartner, E., Hirao, H., 2015. A review of alternative approaches to the reduction of $\mathrm{CO}_{2}$ emissions associated with the manufacture of the binder phase in concrete. Cement and Concrete research, 78, $126-142$.

384 Glukhovsky, V. D., 1959. Soil silicates. Gostroiizdat Publish. Kiev, USSR. 
385 Glukhovsky, V. D., Rostovskaja, G. S., Rumyna, G. V., 1980. High strength slag-alkaline cements. In 386 Proceedings of the $7^{\text {th }}$ international congress on the chemistry of cement, Paris, 164-168.

387 Heitsmann, R. F., Fitzgerald, M., Sawyer, J. L., 1987. U.S. Patent No.4.643.137.

388 Kong, D. L., Sanjayan, J. G., \& Sagoe-Crentsil, K., 2007. Comparative performance of geopolymers made 389 with metakaolin and fly ash after exposure to elevated temperatures. Cement and Concrete Research, $390 \quad 37(12), 1583-1589$.

391 Le Saoût, G., Kocaba, V., Scrivener, K., 2011. Application of the Rietveld method to the analysis of 392 anhydrous cement. Cement and concrete research, 41 (2), 133-148.

393 Liu, Z., Guan, D., Wei, W., Davis, S. J., Ciais, P., Bai, J., ..., Andres, R. J., 2015. Reduced carbon emission estimates from fossil fuel combustion and cement production in China. Nature, 524 (7565), 335-338.

Lucius, M., 1948. Erläuterungen zur geologischen Karte Luxemburgs-Das Gutland. Publications du Service Géologique de Luxembourg, Luxembourg.

Lucius, M., 1950. Geologie Luxemburgs: Erläuterungen zu der geologischen Spezialkarte Luxemburgs. Das Oesling.

Messina, F., Ferone, C., Molino, A., Roviello, G., Colangelo, F., Molino, B., Cioffi, R., 2017. Synergistic recycling of calcined clayey sediments and water potabilization sludge as geopolymer precursors: Upscaling from binders to precast paving cement-free bricks. Construction and Building Materials,

Molino, B., De Vincenzo, A., Ferone, C., Messina, F., Colangelo, F., Cioffi, R., 2014. Recycling of clay 404 sediments for geopolymer binder production. A new perspective for reservoir management in the framework of Italian legislation: The Occhito reservoir case study. Materials, 7 (8), 5603-5616.

Myers, R. J., Bernal, S. A., Provis, J. L., 2017. Phase diagrams for alkali-activated slag binders. Cement and Concrete Research, 95, 30-38.

408 Pacheco-Torgal, F., Castro-Gomes, J., Jalali, S., 2007. Investigations about the effect of aggregates on 409 strength and microstructure of geopolymeric mine waste mud binders. Cement and Concrete $410 \quad$ Research, 37 (6), 933-941. 
411 Pacheco-Torgal, F., Abdollahnejad, Z., Camões, A. F., Jamshidi, M., Ding, Y., 2012. Durability of alkali412 activated binders: a clear advantage over Portland cement or an unproven issue?. Construction and $413 \quad$ Building Materials, 30, 400-405.

414 Paul, M., 2005. Application of the Rietveld method in the cement industry. Proceed. Microstructure $415 \quad$ Analysis in Materials Science, 1-3.

416 Phair, J. W., Van Deventer, J. S. J., 2001. Effect of silicate activator pH on the leaching and material 417 characteristics of waste-based inorganic polymers. Minerals Engineering, 14 (3), 289-304.

418 Poowancum, A., Nimwinya, E., Horpibulsuk, S., 2015. Development of Room Temperature Curing 419 Geopolymer from Calcined Water-Treatment-Sludge and Rice Husk Ash. Calcined Clays for $420 \quad$ Sustainable Concrete, 291-297.

421 Provis, J. L., Van Deventer, J. S. J. (Eds.), 2009. Geopolymers: structures, processing, properties and 422 industrial applications. Elsevier.

423 Provis, J. L., 2014. Geopolymers and other alkali activated materials: why, how, and what?. Materials $424 \quad$ and Structures, 47(1-2), 11-25.

425 Provis, J. L., Palomo, A., Shi, C., 2015. Advances in understanding alkali-activated materials. Cement 426 and Concrete Research, 78, 110-125.

427 Provis, J. L., 2017. Alkali-activated materials. Cement and Concrete Research.

428 Roy, A., Schilling, P. J., Eaton, H. C., Malone, P. G., Brabston, W. N., Wakeley, L. D., 1992. Activation 429 of ground blast-furnace slag by alkali-metal and alkaline-Earth hydroxides. Journal of the American $430 \quad$ Ceramic Society, 75 (12), 3233-3240.

431 Sabir, B. B., Wild, S., Bai, J., 2001. Metakaolin and calcined clays as pozzolans for concrete: a review. $432 \quad$ Cement and Concrete Composites, 23 (6), 441-454

433 Salas, D. A., Ramirez, A. D., Rodríguez, C. R., Petroche, D. M., Boero, A. J., \& Duque-Rivera, J., 2016. 434 Environmntal impacts, life cycle assessment and potential improvement measures for cement 435 production: a literature review. Journal of Cleaner Production, 113, 114-122. 
436 Shi, C., Wu, X., \& Tang, M., 1991. Hydration of alkali-slag cements at $150^{\circ} \mathrm{C}$. Cement and Concrete $437 \quad$ Research, $21(1), 91-100$.

438 Shi, C., Jiménez, A. F., \& Palomo, A., 2011. New cements for the 21st century: the pursuit of an 439 alternative to Portland cement. Cement and concrete research, 41 (7), 750-763.

440 Sun, Z., Cui, H., An, H., Tao, D., Xu, Y., Zhai, J., Li, Q., 2013. Synthesis and thermal behavior of 441 geopolymer-type material from waste ceramic. Construction and Building Materials, 49, 281-287.

442 Tchakoute, H. K., Rüscher, C. H., Djobo, J. N. Y., Kenne, B. B. D., Njopwouo, D., 2015. Influence of 443 gibbsite and quartz in kaolin on the properties of metakaolin-based geopolymer cements. Applied $444 \quad$ Clay Science, 107, 188-194.

445 Wagner, J.-F., 1989. Paläogeographische Entwicklung der triadischen Randfazies Luxemburgs. Z. dt. 446 geol. Ges., (140), Hannover, 311-331.

447 Wang, S. D., Scrivener, K. L., Pratt, P. L., 1994. Factors affecting the strength of alkali-activated slag. $448 \quad$ Cement and concrete research, 24 (6), 1033-1043.

449 Wang, S. D., Scrivener, K. L., 1995. Hydration products of alkali activated slag cement. Cement and $450 \quad$ Concrete Research, 25 (3), 561-571.

451 Wang, S. D., Pu, X. C., Scrivener, K. L., Pratt, P. L., 1995. Alkali-activated slag cement and concrete: a 452 review of properties and problems. Advances in cement research, 7 (27), 93-102.

453 Wianglor, K., Sinthupinyo, S., Piyaworapaiboon, M., Chaipanich, A., 2017. Effect of alkali-activated 454 metakaolin cement on compressive strength of mortars. Applied Clay Science, 141, 272-279.

455 Yunsheng, Z., Wei, S., Zongjin, L., 2010. Composition design and microstructural characterization of 456 calcined kaolin-based geopolymer cement; Applied Clay Science, 47 (3), 271-275. 